\title{
POVEZANOST PSIHOLOŠKIH KARAKTERISTIKA BRAKA SA NAMEROM ŽENA DA TRAŽE PROFESIONALNU PSIHOLOŠKU POMOĆ $^{1}$
}

U cilju utvrđivanja u kojoj meri percepcija različitih aspekata kvaliteta bračnog odnosa i bračna nestabilnost, odnosno, potencijal za razvod braka, doprinose nameri žena da traže profesionalnu psihološku pomoć, ispitano je 777 žena koje žive u formalnom ili neformalnom braku. Kvalitet bračnog odnosa je meren Skalom prilagođenosti u bračnom odnosu (Dyadic Adjustment Scale - DAS: Spanier, 1976, 1989), a bračna nestabilnost je merena pokazateljima potencijala za razvod braka (Booth, Johnson \& Edwards, 1983). Namera da se traži profesionalna psihološka pomoć je ispitana instrumentom (Šakotić-Kurbalija, 2011) koji obuhvata iskustva iz prošlosti, sadašnjosti i nameru da se profesionalna psihološka pomoć traži u budućnosti, kao i razloge zbog kojih ispitanik ima ili nema nameru da traži profesionalnu psihološku pomoć.

Primenom višestruke regresione analize, utvrđeno je da skup analiziranih prediktorskih varijabli statistički jeste značajno povezan sa namerom da se traži profesionalna psihološka pomoć, ali je ta povezanost vrlo niska $\mathrm{R}=0,23(\mathrm{~F}(5,771)=8,28$; $\mathrm{p}<0,000$ ), dok je korigovani $\mathrm{R}^{2}=0,045$; te se značajnijim čini nalaz da na spremnost žena da potraže profesionalnu psihološku pomoć u znatno većoj meri deluju neki drugi faktori. Na osnovu prikupljenih kvalitativnih podataka (pitanjem o razlozima zbog kojih ispitanica ima ili nema nameru da traži profesionalnu psihološku pomoć), pretpostavlja se da značajnu ulogu u nameri žena da traže profesionalnu psihološku pomoć imaju njihovi stavovi prema traženju profesionalne psihološke pomoći, odnosno njihove predrasude po ovom pitanju.

Pošto su rana i adekvatna profesionalna psihološka pomoć osnovni protektivni faktori mentalnog zdravlja, kao implikacija za rad na prevenciji razvoja težih oblika bračne disfunkcionalnosti sledi da je od velikog značaja promovisanje rada institiucija i

1 Istraživanje prikazano ovim radom predstavlja deo projekta „Efekti egzistencijalne nesigurnosti na pojedinca i porodicu u Srbiji“, koji finansira Ministarstvo prosvete i nauke Republike Srbije (DN 179022). 
stručnjaka iz oblasti mentalnog zdravlja.

Ključne reči: brak, kvalitet bračnog odnosa, bračna stabilnost, potencijal za razvod, profesionalna psihološka pomoć.

\section{UVOD}

Epidemiološke studije ukazuju na opšti porast psihopatoloških stanja, a posebno depresivnih poremećaja, čija se prevalenca, prema različitim studijama, u opštoj populaciji kreće od 2-4\% (Timotijević i Draganić-Gajić 2007). Savremene epidemiološke studije, takođe, ukazuju da istovremeno postoji i problem nespremnosti velikog broja ljudi da traže pomoć stručnjaka za mentalno zdravlje, iako imaju neke od psiholoških problema i mentalnih poremećaja. Imajući ovo u vidu, širom sveta su pokrenuta brojna istraživanja činilaca koji doprinose spremnosti da se traži stručna psihološka pomoć.

Istraživanja u sferi traženja profesionalne psihološke pomoći, a posebno istraživanja koja imaju za cilj utvrđivanje prediktora za traženje profesionalne psihološke pomoći, imaju veliki praktični značaj - daju smernice za osmišljavanje i razvoj strategija za adekvatno promovisanje rada institiucija i stručnjaka iz oblasti mentalnog zdravlja. Ovo je veoma značajno ako se ima u vidu da su rana i adekvatna profesionalna psihološka pomoć osnovni protektivni faktori mentalnog zdravlja.

Rezultati znatnog broja sprovedenih istraživanja (npr. Deane i Chamberlain 1994; Kelly \& Achter 1995; Deane \& Todd 1996; Bayer \& Peay 1997; Cepeda-Benito \& Short 1998; Cramer 1999; Carlton \& Deane 2000) nedvosmisleno pokazuju da osobe koji imaju pozitivne stavove prema traženju profesionalne psihološke pomoći snažnije izražavaju nameru da traže pomoć, u odnosu na osobe koje imaju negativne stavove prema traženju profesionalne psihološke pomoći

Takođe su značajni i rezultati brojnih istraživanja (npr. Halgin et al. 1987; Deane \& Todd 1996; Bringle \& Byers 1997; Carlton \& Deane 2000; Ciarrochi et al. 2002) koji pokazuju da je postojeće iskustvo u traženju profesionalne psihološke pomoći pouzdan pokazatelj namere da se profesionalna psihološka pomoć traži i u sadašnjosti, odnosno u budućnosti, ukoliko postoji potreba za njom.

Svakako ne treba gubiti iz vida ni nalaze da se ovo odnosi samo na one psihološke probleme gde je ranije iskustvo traženja profesionalne psihološke pomoći 
omogućilo da se traženje stručne pomoći vidi kao korisna mogućnost za rešavanje njihovih problema (Deane \& Todd 1996). Odnosno, opažena korisnost ranije pružene profesionalne psihološke pomoći je značajno povezana sa spremnošću osobe da traži profesionalnu psihološku pomoć i u budućnosti (Surgenor 1985).

Savremene analize braka (Fincham \& Beach 2010) imaju za osnovni cilj poboljšanje preventivnih intervencija kroz identifikaciju faktora rizika za javljanje nepovoljnih ishoda braka. U cilju poboljšanja preventivnih psiholoških intervencija, istraživanje čiji prikaz sledi, ispituje povezanost bračne stabilnosti, različitih aspekata kvaliteta bračnog odnosa i namere da se traži profesionalna psihološka pomoć.

Uzimajući u obzir:

- da su brojna istraživanja pokazala da se zadovoljstvo brakom smanjuje dolaskom deteta u porodicu, i to posebno u percepciji žena (Ade-Rider \& Braubacker 1983; Chester 1982; Belsky, Spanier \& Rovine 1983; Belsky, Lang \& Rovine 1985; Belsky \& Pensky 1988),

- da majčinstvo znatno više deluje na život žene, nego što očinstvo deluje na život muškarca (Nomaguchi \& Milkie 2003),

- da se bračno zadovoljstvo žena pokazalo značajnijim za stabilnost braka (Heaton \& Blake 1999, Obradovic \& Cudina-Obradovic 2000), i

- da se ženina percepcija kvaliteta bračnog odnosa pokazala kao prvi i najvažniji faktor koji vodi ka razvodu ili pomaže u prevenciji razvoda (Karney \& Bradbury 1995; Cross \& Madson 1997),

predmet istraživanja prikazanog ovim radom su bile relacije bračne stabilnosti i percepcije različitih aspekata kvaliteta bračnog odnosa kod žena koje imaju dete/ decu, sa njihovom namerom da traže profesionalnu psihološku pomoć. Tačnije, istraživački problem prikazanog istraživanja predstavlja pitanje mogu li se ženina percepcija kvaliteta bračnog odnosa i potencijal za razvod braka (kao psihološke karakteristike braka) smatrati značajnim prediktorima ženine namere da potraži profesionalnu psihološku pomoć?! 
Podaci su prikupljeni na ukupnom uzorku od 777 žena koje žive u formalnom ili neformalnom braku i imaju jedno ili više dece.

Prediktorske varijable u ovom istraživanju predstavljaju različite dimenzije kvaliteta bračnog odnosa i bračna nestabilnost, dok kriterijsku varijablu predstavlja namera da se traži profesionalna psihološka pomoć.

Kvalitet bračnog odnosa je ispitan Spanier-ovom Skalom prilagođenosti u bračnom odnosu (Dyadic Adjustment Scale, DAS-7, Spanier 1976, 1989). Skala se sastoji od 32 ajtema na koje ispitanici odgovaraju tako što procenjuju stepen slaganja na šestostepenoj skali koja se odnosi na učestalost određenih ponašanja, ili procenjuju da li su neka ponašanja prisutna u njihovoj vezi. Skala je, na osnovu rezultata faktorske analize, podeljena na četiri subskale:

1) Konsenzus (sastoji se od 13 stavki u kojima se procenjuje stepen slaganja partnera u sledećim oblastima:

- vođenje porodičnih finansija,

- rekreacija,

- odnos prema religiji,

- odnosi sa prijateljima,

- ponašanje u uobičajenim situacijama,

- životna filozofija - smisao života,

- odnosi sa roditeljima i rođacima,

- verovanje u značaj nekih stvari, ciljeva i dostignuća,

- količina vramena provedenog zajedno,

- donošenje zajedničkih odluka,

- kućne obaveze,

- interesi i aktivnosti u slobodnom vremenu,

- $\quad$ odluke vezane za profesiju - posao;

2) Zadovoljstvo brakom se sastoji od 10 stavki koje se odnose na:

- učestalost razmišljanja o tome kako bi bilo biti u vezi ili braku s nekim drugim,

- učestalost završanja bračnog konflikta impulsivnim izlaskom iz kuće jednog od bračnih partnera,

- učestalost razmišljanja o tome da bračni odnos "ide dobro", 
- učestalost žaljenja zbog ulaska u brak,

- učestalost bračnih konflikata,

- učestalost doživljaja međusobnog iritiranja bračnih partnera,

- stepen poverenja u bračnog partnera,

- učestalost ljubljenja bračnog partnera,

- stepen generalnog zadovoljstva bračnim odnosom,

- lični odnos prema budućnosti braka i stepen spremnosti na lično angažovanje u njegovom očuvanju;

3) Kohezivnost obuhvata 5 stavki koje se odnose na zajedničko provođenje vremena i učestalost sledećih aktivnosti:

- podsticanje razmene ideja,

- zajednički smeh,

- smiren razgovor / diskusija o nečemu,

- zajednički rad na nekom poslu / ostvarenju, i

- brojnost zajedničkih interesovanja bračnih partnera van kuće;

4) Afektivno-seksualna usaglašenost se sastoji od 4 ajtema kojima se procenjuje:

- $\quad$ stepen međusobnog slaganja bračnih partnera u izražavanju emocija,

- stepen međusobnog slaganja bračnih partnera u seksualnim odnosima,

- da li nezainteresovanost za seksualni odnos usled iscrpljenosti ili umora dovodi do problema u bračnom odnosu, i

- da li nepokazivanje ljubavi dovodi do problema u bračnom odnosu.

Bračna stabilnost je merena potencijalom za razvod (Booth, Johnson i Edwards 1983). Ova skala procene uključuje 3 stavke: da li je ispitivana osoba u proteklih godinu dana:

- razmišljala o razvodu braka,

- $\quad$ razgovarala sa prijateljima o razvodu braka, $\mathrm{i}$

- $\quad$ razgovarala sa bračnim partnerom o razvodu braka. 
Namera da se traži profesionalna psihološka pomoć je ispitana instrumentom (Šakotić-Kurbalija, 2011) koji obuhvata iskustva iz prošlosti, sadašnjosti i nameru da se profesionalna psihološka pomoć traži u budućnosti, kao i razloge zbog kojih ispitanica ima ili nema nameru da traži profesionalnu psihološku pomoć.

U cilju utvrđivanja u kojoj meri percepcija različitih dimenzija kvaliteta bračnog odnosa i bračna stabilnost, odnosno, potencijal za razvod braka, doprinose nameri žena da traže profesionalnu psihološku pomoć primenjena je višestruka regresiona analiza.

\section{REZULTATI ISTRAŽIVANJA}

Rezultati pokazuju da je skup analiziranih prediktorskih varijabli statistički značajno povezan sa namerom da se traži profesionalna psihološka pomoć, ali je količina objašnjene varijanse vrlo skromna. Dobijen je koeficijent multiple korelacije $\mathrm{R}=0,23(\mathrm{~F}(5,771)=8,28 ; \mathrm{p}<0,000)$, dok je korigovani $\mathrm{R}^{2}=0,045$, što govori da postoji samo oko $4,5 \%$ zajedničke varijanse.

$\mathrm{U}$ tabeli 1 su prikazani regresioni parametri i indikatori statističke značajnosti za sve prediktorske varijable.

Tabela 1 Regresioni parametri i indikatori statističke značajnosti prediktorskih varijabli

\begin{tabular}{lcccccc}
\hline & $\mathrm{B}$ & $\begin{array}{c}\text { St. } \\
\text { greška }\end{array}$ & Beta & $\mathrm{t}$ & $\mathrm{p}$ & $\begin{array}{c}\text { Parcijalna } \\
\text { korelacija }\end{array}$ \\
\hline (Constant) & 1.700 & .224 & & 7.588 & .000 & \\
Potencijal za razvod & .135 & .038 & .151 & 3.550 & .000 & .127 \\
Kohezivnost & .036 & .010 & .193 & 3.653 & .000 & .130 \\
Afektivno-seksualna usaglašenost & -.036 & .017 & -.100 & -2.069 & .039 & -.074 \\
Zadovoljstvo brakom & -.009 & .007 & -.083 & -1.371 & .171 & -.049 \\
Konsenzus & -.003 & .005 & -.032 & -.558 & .577 & -.020 \\
\hline
\end{tabular}

Kao što se može videti iz tabele 1 , namera ispitanica da traže profesionalnu psihološku pomoć je značajno povezana sa potencijalnom za razvod, kohezijom para (količinom zajedničkih interesovanja i aktivnosti sa suprugom) i niskom afektivnoseksualnom usaglašenošću (kvalitetom seksualnog odnosa i otvorenošću u razmeni osećanja sa suprugom). 


\section{DISKUSIJA}

Rezultati dobijeni ovim istraživanjem pokazuju da je, u celini posmatran, skup prediktorskih varijabli koji čine različiti parametri kvaliteta bračnog odnosa i stabilnost braka, statistički značajno povezan s namerom žena da traže profesionalnu psihološku pomoć, što zvuči potpuno logično i očekivano. Međutim, treba imati u vidu da je samo $4,5 \%$ varijanse namere da se traži profesionalna psihološka pomoć objašnjeno prediktorskim setom varijabli vezanim za kvalitet i stabilnost bračnog odnosa, pa se na osnovu toga može zaključiti da je povezanost kvaliteta i stabilnosti braka sa namerom da se traži profesionalna psihološka pomoć, iako statistički značajna, veoma niska.

Odnosno, doživljaj žena o (ne)kvalitetu bračnog odnosa i bračna (ne) stabilnost vrlo malo doprinose njihovoj nameri da traže profesionalnu psihološku pomoć.

Pri tom je, od pojedinačno posmatranih varijabli iz ovog skupa, namera ispitanica da traže profesionalnu psihološku pomoć statistički značajno povezana sa potencijalnom za razvod, kohezijom para (količinom zajedničkih interesovanja i aktivnosti sa suprugom) i niskom afektivno-seksualnom usaglašenošću, a nije statistički značajno povezana sa stepenom slaganja para niti sa stepenom bračnog zadovoljstva ispitanica.

U skladu s napred navedenim nalazima o traženju profesionalne psihološke pomoći su i kvalitativni odgovori na pitanje o razlozima zbog kojih ispitanica ima ili nema nameru da traži profesionalnu psihološku pomoć. Najčešći odgovori onih koje nemaju nameru da traže profesionalnu psihološku pomoć su da nemaju potrebu "za psihologom", u smislu da njihov "problem nije toliko veliki” (bez obzira na to kako percipira svoj bračni odnos), a zatim, s nešto slabijom učestalošću, slede odgovori koji se odnose na postojanje nezadovoljavajućih iskustva iz prošlosti, u vezi sa dobijenom profesionalnom psihološkom pomoći.

Pošto su rana i adekvatna profesionalna psihološka pomoć osnovni protektivni faktori mentalnog zdravlja, kao implikacija za rad na prevenciji razvoja težih oblika bračne disfunkcionalnosti sledi da je od velikog značaja promovisanje rada institiucija i stručnjaka iz oblasti mentalnog zdravlja.

Ukoliko se prihvati činjenica da ni jedan bračni odnos (pa ni onaj 
najfunkcionalniji) nije i ne može biti bez bračnih konflikata i bez neugodnih osećanja, ostaje pitanje kada je i koliko neugodnih osećanja i frustracije korisno istolerisati, da bi prevladavanje krize rezultiralo individualnim i bračnim razvojem, a kada i koliko neugodnih osećanja i frustracije označava ličnu i/ili bračnu psihopatologiju koja se ne može i neće prevladati ma koliko se "trudili"?! I u kom trenutku "treba" potražiti profesionalnu psihološku pomoć?!

Ma koliko istraživanja sproveli, na prvo pitanje nikada neće moći da se da precizan odgovor koji će važiti za sve ljude. Mogu se dati samo neke generalne preporuke i potencijalnim klijentima i psihoterapeutima (Šakotić-Kurbalija 2010), a lični odgovor na ovo pitanje je najbolje temeljno istražiti uz profesionalnu psihološku pomoć! Kada je pravo vreme za to? - Čim se prepozna da je poremećena bračna ravnoteža.

Ljudi po pravilu traže profesionalnu psihološku pomoć s namerom da nauče kako da promene partnera i/ili neke spoljašnje okolnosti. Međutim, do promene u njihovom bračnom/porodičnom funkcionisanju će doći tek kada, uz stručnu pomoć, shvate da samo ličnom promenom mogu postići pozitivan ishod (nekada je to kvalitetniji bračni odnos, a nekada je to razvod braka). U svakom slučaju, do promene će doći tek kada kod nezadovoljne osobe postoji spremnost da se ona lično menja, umesto da želi, očekuje i traži promenu partnera ili životnih okolnosti!

\section{ZAKLJUČAK}

U celini posmatrane, psihološke karakteristike braka (različiti aspekti kvaliteta bračnog odnosa i bračna (ne)stabilnost) statistički značajno doprinose nameri žena da traže profesionalnu psihološku pomoć.

Pri tom, nameri da se potraži profesionalna psihološka pomoć, pojedinačno, najviše doprinosi ženino razmatranje razvoda (bračna nestabilnost/visok potencijal za razvod), potom ženin doživljaj kohezivnosti u bračnom odnosu (doživljaj postojanja međusobne povezanosti i kvalitetne komunikacije među partnerima), a značajan neposredni doprinos nameri žene da traži profesionalnu psihološku pomoć daje i njen doživljaj da su bračni problemi uzrokovani njenom i suprugovom neusaglašenošću vezanom za seksualne odnose i/ili njihovom neusaglašenošću po pitanju ispoljavanja emocija. 
Bračno (ne)zadovoljstvo (stepen opšteg zadovoljstva bračnim odnosom, stepen poverenja u partnera, učestalost bračnih konflikata, doživljaj međusobne netrpeljivosti i odnos prema budućnosti braka), kao i doživljaj (ne)slaganja partnera po pitanjima vezanim za svakodnevno bračno funkcionisanje (vođenje finansija, odnos prema religiji, ispoljavanje osećanja, odnos prema roditeljima i rođacima, životna filozofija i sl.) nemaju direktan uticaj na nameru žena da potraže profesionalnu psihološku pomoć.

Treba imati u vidu da na spremnost žena da potraže profesionalnu psihološku pomoć znatno više deluju neki drugi faktori, u odnosu na karakteristike bračnog odnosa, te bi u cilju utvrđivanja prediktora namere da se traži profesionalna psihološka pomoć, u daljim istraživanjima najkorisnije bilo istraživati/utvrditi razlike između onih koji su aktuelno u procesu dobijanja profesionalne psihološke pomoći, onih koji imaju nameru, ali još nisu tražili profesionalnu pomoć i onih koji nemaju nameru da traže profesionalnu psihološku pomoć.

\section{LITERATURA}

Ade-Ridder, L. \& Brubacker , T . H. (1983.). The quality of long-term marriages, u: T .H. Brubacker (Ed.), Family Relationships in Later Life, Beverly Hills, Sage Publications.

Bayer, J. K., \& Peay, M. Y. (1997). Predicting intentions to seek help from professional mental health services. Australian and New Zealand Journal of Psychiatry, 31, $504-513$.

Belsky, J. \& Pensky, E. (1988). Marital change across the transition to parenthood. Marriage \& Family Review, 12, 133-156.

Belsky, J., Lang, M. E. \& Rovine, M. (1985). Stability and Change in Marriage Across the Transition to Parenthood: A Second Study. Journal of Marriage and Family, 47, 855-865.

Belsky, J., Spanier, G. B. \& Rovine, M. (1983). Stability and Change in Marriage Across the Transition to Parenthood. Journal of Marriage and Family, 45, 567-578.

Booth, A., Johnson, D., \& Edwards, J. N. (1983). Measuring Martial Instability. Journal of Marriage and the Family, 45, 387-393. 
Bringle, R. G. and Byers, D. (1997). Intentions to Seek Marriage Counseling. Family Relations, Vol. 46, No. 3 , pp. 299-304.

Carlton, P. A., \& Deane, F. P. (2000). Impact of attitudes and suicidal ideation on adolescents' intentions to seek professional help. Journal of Adolescence, 23, 3545 .

Cepeda-Benito, A., \& Short, P. (1998). Self-concealment, avoidance of psychological services, and perceived likelihood of seeking professional help. Journal of Counseling Psychology, 45, 58 - 64.

Chester, R. (1982). Children and Marital Problems. International Journal of Sociology \& Social Policy, 2, 5-27

Ciarrochi, J., Deane, F. P., Wilson, C. J., \& Rickwood, D. (2002). Adolescents who need help the most are the least likely to seek it: The relationship between low emotional competence and low intention to seek help. British Journal of Guidance and Counselling, 30, 173-188.

Cramer, K. M. (1999). Psychological antecedents to help-seeking behavior: A reanalysis using path modeling structures. Journal of Counseling Psychology, 46, 381-387.

Cross, S.E., \& Madson, L. (1997). Models of the self: Self-Construals and gender. Psychological Bulletin, 122, 5-37.

Deane, F. P., \& Chamberlain, K. (1994). Treatment fearfulness and distress as predictors of professional psychological help-seeking. British Journal of Guidance and Counselling, 22, 207-217.

Deane, F. P., \& Todd, D. M. (1996). Attitudes and intentions to seek professional psychological help for personal problems or suicidal thinking. Journal of College Student Psychotherapy, 10, 45-59.

Fincham, F. D., \& Beach, S. R. H. (2010). Marriage in the New Millennium: A Decade in Review. Journal of Marriage and Family, 72, 630-649.

Halgin, R. P., Weaver, D. D., Edell, W. S., \& Spencer, P. G. (1987). Relation of depression and help-seeking history to attitudes toward seeking professional psychological help. Journal of Counseling Psychology, 34, 177-185.

Heaton, T. B., \& Blake, A. M. (1999). Gender differences in determinants of marital disruption. Journal of Family Issues, 20, 25-45.

Karney, B. R., \& Bradbury, T. N. (1995). Assessing longitudinal change in 
marriage: An introduction to the analysis of growth curves. Journal of Marriage and the Family, 57, 1091-1108.

Kelly, A. E., \& Achter, J. A. (1995). Self-concealment and attitudes toward counseling in university students. Journal of Counseling Psychology, 42, 40 - 46.

Nomaguchi, K. M. \& Milkie, M. A. (2003). Costs and Rewards of Children: The Effects of Becoming a Parent on Adults. Journal of Marriage \& Family, 65, 356374

Obradovic, J., \& Cudina-Obradovic, M.(2000). Correlates of subjective global merital

Spanier, G. B. (1976). Measuring dyadic adjustment: New scales for assessing the quality of marriage and similar dyads. Journal of Marriage and the Family, 38, $15-28$

Spanier, G.B. (1989). Manual for the dyadic adjustment scale. North Tonowanda, New York: Multi-Health Systems.

Surgenor, L. J. (1985). Attitudes toward seeking professional psychological help. New Zealand Journal of Psychology, Vol 14(1), 27-33.

Timotijević, I., Draganić-Gajić, S. (2007). Poremećaji raspoloženja. U Jašović-Gačić, M., Lečić-Toševski, D.(ur). Psihijatrija. Beograd: Univerzitet u Beogradu. Medicinski fakultet.

Šakotić-Kurbalija， J. (2010). Zavisnost u partnerskim odnosima i psihoterapijske implikacije. Godišnjak Filozofskog fakulteta, Novi Sad, 35(1), 169179.

Jelena Šakotić-Kurbalija

Filozofski fakultet Univerziteta u Novom Sadu

jelenas@neobee.net

RELATIONSHIPS BETWEEN PSYCHOLOGICAL CHARACTERISTICS OF MARRIAGE AND THE INTENTION OF WOMEN TO SEEK PROFESSIONAL PSYCHOLOGICAL HELP ${ }^{2}$

2 The research presented in this paper is a part of the project "Effects of existential uncertainty on individual and family in Serbia" funded by the Ministry of Education and Science of the Republic of Serbia (DN 179022). 
Summary: In order to determine the extent to which perceptions of various aspects of the quality of marriage and marital instability, i.e. the potential for divorce, is related to the intention of women to seek professional psychological help, we were examined 777 wives living in the formal or informal marriage.

The quality of the marital relationship was measured by a Dyadic Adjustment Scale DAS (Spanier, 1976, 1989), and marital instability was measured by indicators of the potential for divorce (Booth, Johnson, \& Edwards, 1983). Intention to seek professional psychological help was measured with the instrument (Šakotić-Kurbalija, 2011), which includes past and present experiences, intention to seek professional psychological help in the future, as well as the reasons why the respondent has or does not intend to seek professional psychological help.

The results of the multiple regression analysis are suggesting that a correlation between the set of predictors and the intention of wives to seek professional psychological help is statistically significant, but the association is very low $R=0.23(F(5.771)=8.28, p$ $<0.000$ ) while the adjusted $\mathrm{R}^{2}=0.045$, thus it seems that the intention to seek professional psychological help is much more influenced by another factors.

Based on the qualitative data collected in this study (questions about why women have or do not intend to seek professional psychological help), it is assumed that the attitudes toward seeking professional psychological help, and their prejudices on this issue play important role in forming their intentions and actual seeking of professional psychological assistance.

Since the early and adequate professional psychological support is one of the basic protective factors of mental health, therefore is of great importance to promote the work of professionals and mental health agencies.

Key words: marriage, marital satisfaction, marital quality, marital stability, potential for divorce, professional psychological help. 